\title{
Potencial do Extrativismo da Castanha-do-Pará na Geração de Renda em Comunidades da Mesorregião Baixo Amazonas, Pará
}

\author{
Adriano Araújo Silva ${ }^{1}$, Maria Kelliane Valentim Santos ${ }^{2}$, \\ João Ricardo Vasconcelos Gama ${ }^{3}$, Rommel Noce ${ }^{3}$, Sandro Leão ${ }^{3}$ \\ ${ }^{1}$ Departamento de Recursos Naturais, Instituto Federal de Educação, \\ Ciência e Tecnologia do Pará - IFPA, Santarém/PA, Brasil \\ ${ }^{2}$ Departamento de Engenharia Florestal, Universidade Federal do Oeste do Pará (Ensino) - UFOPA, Santarém/PA, Brasil \\ ${ }^{3}$ Departamento de Engenharia Florestal, Universidade Federal do Oeste do Pará (Diretoria de Ensino) - UFOPA, \\ Santarém/PA, Brasil
}

\begin{abstract}
RESUMO
Objetivou-se, neste estudo, caracterizar a extração e analisar a viabilidade financeira do extrativismo da castanha-do-pará em três municípios da mesorregião Baixo Amazonas, Estado do Pará. Foram realizadas entrevistas com 40 extrativistas e nove atravessadores, selecionados em amostragem não probabilística e intencional. A viabilidade econômica foi estimada por meio de custo de extração, receita líquida (RL), remuneração da mão de obra familiar (RMOF) e renda do trabalho familiar (RTF). A RTF foi de R $\$ 2.419,56$ (Almeirim), R $\$ 983,22$ (Óbidos) e R $\$$ 831,03 (Oriximiná). A RMOF da extração foi de $\mathrm{R} \$ 24,69, \mathrm{R} \$ 23,98$ e $\mathrm{R} \$ 26,47$, respectivamente, próxima ao custo de oportunidade evidenciado na região de estudo. A extração da castanhado-pará apresentou-se financeiramente viável para os extrativistas, com a remuneração da mão de obra familiar igual ou superior ao custo de oportunidade da região, sendo mais uma fonte de renda para os comunitários da Amazônia, além de promover a conservação da floresta.
\end{abstract}

Palavras-chave: Bertholletia excelsa, mão de obra familiar, produto florestal não madeireiro.

\section{Potential of Brazil nut Extraction to Generate Income in the Communities of the Lower Amazon Mesoregion, Brazil}

\begin{abstract}
The objective of this study was to characterize the extraction and analyze the financial viability of Brazil nut extraction in three municipalities in the Lower Amazon Mesoregion, state of Para, Brazil. Interviews were conducted with 40 workers and 9 dealers selected by intentional nonprobabilistic sampling. Economic viability was estimated by extraction cost, net revenue (NR), family labor remuneration (FLR), and family labor income (FLI). The following amounts of FLI were recorded: $R \$ 2,419.56$ (Almeirim), $R \$ 983.22$ (Obidos) and $R \$ 831.03$ (Oriximiná). The FLR amounts for extraction were $\mathrm{R} \$ 24.69, \mathrm{R} \$ 23.98$, and $\mathrm{R} \$ 26.47$, respectively for the municipalities above mentioned, which were close to the opportunity cost for the study region. The extraction of Brazil nuts appears to be financially viable for extraction workers, with family labor remuneration equals or greater than the opportunity cost of the region. Besides promoting the conservation of the forest, this activity is also an extra source of income for the Amazonian community.
\end{abstract}

Keywords: Bertholletia excelsa, family labor, non-timber forest product. 


\section{INTRODUÇÃO}

A castanheira (Bertholletia excelsa Bonpl.) pertence à família Lecythidaceae. É uma espécie arbórea nativa da Amazônia, que tem por habitat as terras não inundáveis. Árvore símbolo da Amazônia, em virtude da sua importância social, ecológica e econômica para a região, sua distribuição geográfica é ampla e abrange as florestas de Venezuela, Colômbia, Peru, Bolívia e Guiana. Porém, as formações de florestas mais densas ocorrem no Brasil (Lorenzi, 2000; Sá et al., 2008; Salomão, 2009; Scoles et al., 2008). A castanheira pode formar aglomerações (castanhais) com densidades entre 15 e 20 indivíduos por hectare (Mori \& Prance, 1990; Scoles \& Gribel, 2011).

A castanha-do-pará, como é denominado o fruto da castanheira, teve, entre outros produtos extrativos, grande importância na formação econômica, social e política da Amazônia, e está entre os produtos mais comercializados no mercado nacional e de exportação. O extrativismo e o beneficiamento das amêndoas sustentam inúmeras comunidades da Amazônia e movimentam suas economias regionais, ao mesmo tempo em que promovem a conservação da floresta (Sá et al., 2008; Homma, 2012).

Entretanto, não existe consenso sobre a viabilidade econômica desta atividade; em especial, há divergências sobre a sua atividade de base - a coleta. Alguns autores argumentam que o extrativismo, mesmo com baixo nível tecnológico, é alternativa viável de fonte de renda para as populações que precisam dos recursos florestais para sobreviver (Cavalcante, 2002; Bayma et al., 2009). Para Shackleton et al. (2007), a castanha, além de ser um alimento, tem outro ponto positivo: o excedente da coleta é comercializado, minimizando o avanço da pobreza. Fiedler et al. (2008) destacam que o extrativismo é importante, pois, além de contribuir com a renda familiar, desacelera ou impede, em alguns locais, o avanço do desmatamento.

Outros autores, porém, entendem que o extrativismo é uma atividade com produtividade declinante e, portanto, mostra-se economicamente inviável. Homma (2012) considera que alguns fatores são indutores desse declínio, tais como: o aumento no custo da extração, uma vez que as melhores áreas de castanhais tornam-se cada vez mais difíceis; o esgotamento das reservas naturais; o aumento da demanda; a expansão da fronteira agrícola; a criação de alternativas econômicas; o surgimento de produtos substitutos, e o aumento do custo de oportunidade de trabalho no meio rural, dentre outros. Para Procópio (2007), o extrativismo é incapaz de aliviar a pobreza ou incrementar substancialmente a renda monetária, podendo ocorrer um 'subdesenvolvimento sustentável'.

Entretanto, em meio a essa discussão teórica de cunho econômico, dados do IBGE (2010) mostram que, dentre os produtos do extrativismo vegetal, a castanha-do-pará merece destaque, por ter movimentado 55,2 milhões de reais, ocupando a sexta colocação, em valor comercializado, entre os produtos do extrativismo no Brasil no ano 2009. Do total de 40.357 toneladas de castanha extraída no Brasil, 96,3\% são oriundos de florestas da Região Norte do Brasil. O Estado do Pará, em terceiro lugar, corresponde a 8.128 toneladas (20,14\% da produção), gerando uma receita da ordem de 10,13 milhões de reais. Deste montante, a região de integração Baixo Amazonas foi responsável por contribuir com $98,24 \%$. No Pará, os municípios que mais extraíram a castanha, no ano de 2010, foram Oriximiná, com 2.100 toneladas $(5,2 \%$ da produção brasileira), Óbidos, com 1.750 toneladas (4,3\%) - quinto e sexto lugares, respectivamente, no ranking de produção no Brasil - e Almeirim, que contribuiu com 166 toneladas (IBGE, 2010).

É neste cenário de discussões acerca da viabilidade econômica da extração da castanha-dopará que este trabalho objetiva descrever a extração e a comercialização desse produto, além de analisar a renda obtida com essa atividade nos municípios de Oriximiná, Óbidos e Almeirim, localizados na região de integração Baixo Amazonas, Estado do Pará.

\section{MATERIAL E MÉTODOS}

\section{1. Área de estudo}

A coleta de dados ocorreu nos municípios Oriximiná, Óbidos e Almeirim, localizados na mesorregião Baixo Amazonas, região oeste do Estado do Pará (Figura 1). Conforme a classificação 

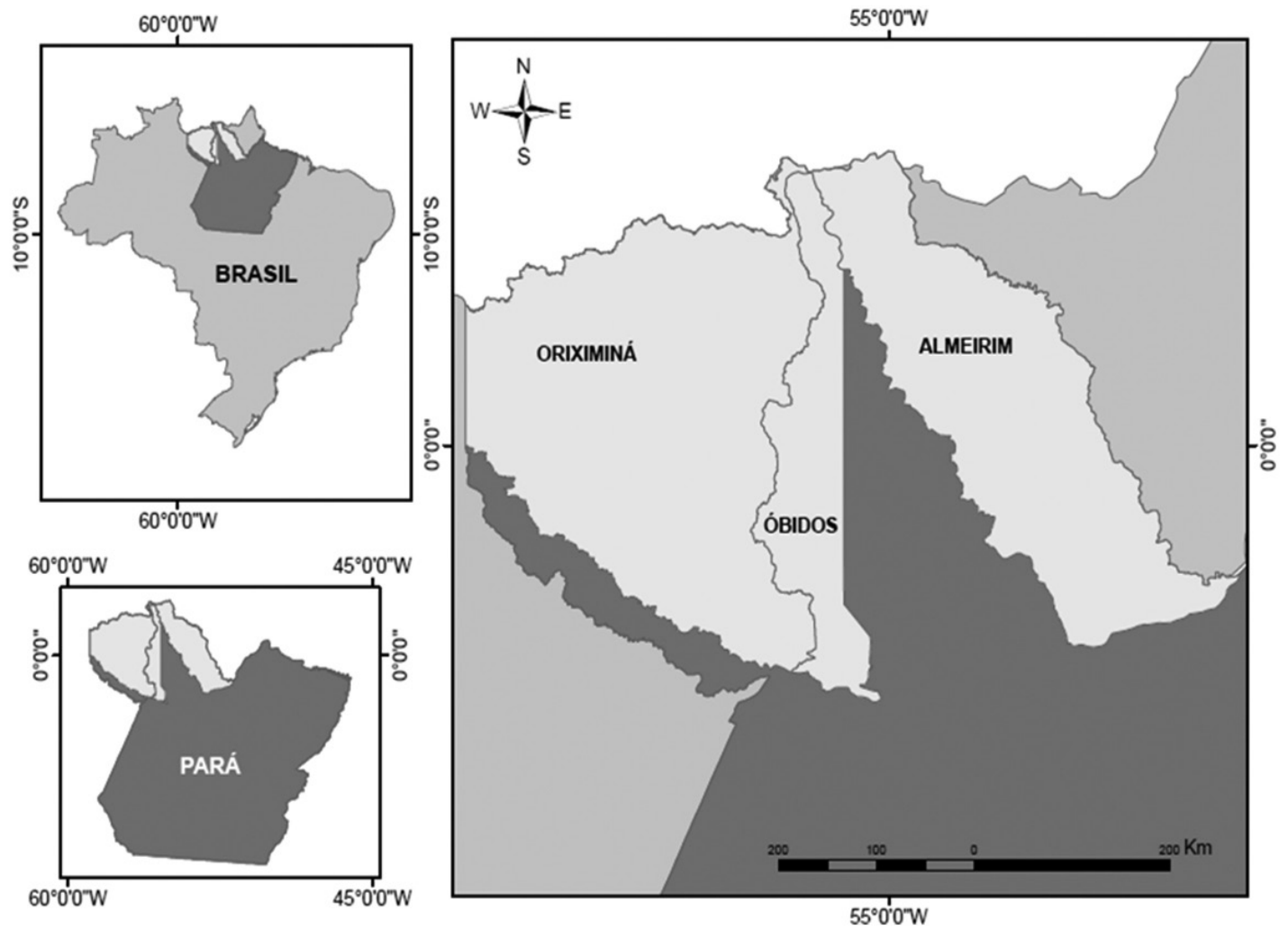

Figura 1. Mapa de localização dos três municípios estudados, Mesorregião Baixo Amazonas, Estado do Pará. Figure 1. Location map of the three cities studied, Mesoregion Lower Amazon, Pará State.

de Koppen, os três municípios apresentam o clima do tipo Ami, com temperaturas sempre elevadas - valores médios para as máximas de $31^{\circ} \mathrm{C}$ e, para as mínimas, de $22,5^{\circ} \mathrm{C}$-, com média anual de $25,6{ }^{\circ} \mathrm{C}$. A pluviosidade se aproxima dos $2.000 \mathrm{~mm}$ anuais, com distribuição irregular durante o ano. A estação chuvosa ocorre de dezembro a junho, sendo março o mês mais chuvoso. A estação de menor pluviosidade é de julho a dezembro, apresentando totais mensais inferiores a $60 \mathrm{~mm}$ (Pará, 2012a, b, c).

\subsection{Coleta de dados}

Neste estudo, destacam-se dois atores sociais: 1) o extrativista, também denominado de castanheiro ou coletor da castanha; 2) os atravessadores, que são agentes intermediários da comercialização, comerciantes da própria comunidade oriundos de outros locais, que vão até as comunidades apenas para comprar a castanha.

Os dados foram obtidos através de entrevistas com os coletores e atravessadores de castanha nos municípios, por meio de questionário semiestruturado e específico para cada categoria (Tabela 1), com a finalidade de obter informações, tais como: situação fundiária das áreas utilizadas para coleta, formas de extração, volume coletado, mão de obra utilizada, custo dos serviços e materiais, comercialização, limitações e potencialidades da atividade de extração.

Os entrevistados foram selecionados por amostragem não probabilística, pela técnica 'bola de neve' (Albuquerque et al., 2010). Essa técnica é uma forma de amostra em que os participantes iniciais de um estudo indicam novos participantes do universo a ser estudado, os quais, por sua vez, indicam novos participantes e, assim sucessivamente, até que seja alcançado o objetivo proposto. Ou seja: alcança-se o momento em que os novos entrevistados passam a repetir as informações já obtidas em entrevistas anteriores, sem acrescentar novas informações quantitativas e qualitativas relevantes à pesquisa (WHO, 1994). 
Tabela 1. Número de entrevistados para coleta de dados dos três municípios estudados, Mesorregião Baixo Amazonas, Estado do Pará.

Table 1. Number of interviewed for data base of the three cities studied, Mesoregion Lower Amazon, Pará State.

\begin{tabular}{llcc}
\multirow{2}{*}{ Município } & \multicolumn{1}{c}{ Comunidades } & \multicolumn{2}{c}{ Entrevistados } \\
\cline { 3 - 4 } Almeirin & Arumanduba, Recreio e Cafezal & Coletores & Atravessadores \\
Oriximiná & $\begin{array}{l}\text { São Francisco de Canidé, Pancada, Moura, Poção, São José, } \\
\text { Nova Betel e Poço Fundo }\end{array}$ & 18 & 3 \\
Óbidos & Cruzeirão, Cipoal, Paiol, Castanhanduba e Bom Sossego & 13 & 3 \\
\hline
\end{tabular}

\subsection{Análise econômica}

A estimativa do custo de extração de castanha foi realizada por meio da quantificação das despesas nas etapas do processo de coleta (Sá et al., 2008; Lopes et al., 2011). Foram considerados os custos do equipamento de segurança (espingarda), utilizando-se a depreciação do bem apropriado pelo método linear (Nascimento Jr et al., 2000), além das despesas com manutenção e proporção de uso na atividade durante o ano. Consideraram-se, também, como despesa, ferramentas e utensílios de coleta, transporte, munição de arma de fogo para proteção e mão de obra empregada - conjunto de itens apropriado ao seu custo de oportunidade na região -, além de utensílios pessoais que se desgastam ao longo dos períodos de coleta, como botas, calças e camisas.

Este trabalho analisou a geração de renda da coleta da castanha-do-pará para o extrativista, sem considerar o custo da terra, uma vez que a atividade de extração ocorre em áreas do governo e/ou de terceiros, que não cobram pela atividade; não há, portanto, imobilização de capital. Como não houve investimento na formação dos castanhais nativos, não há capital patrimonial a ser recuperado nestas áreas. Os preços dos fatores de produção e dos produtos foram quantificados em valores reais e em moeda nacional (reais), com base na média da safra de 2010.

Para se determinar a viabilidade econômica da atividade, foram utilizados como indicadores a receita líquida (RL) e a remuneração da mão de obra familiar (RMOF). A RL foi obtida pela diferença entre a receita bruta e os custos; a RMOF foi estimada a partir da relação entre a renda do trabalho familiar (RTF) e o número de homem.dia ${ }^{-1}$ (diárias) de mão de obra utilizada na extração; a
RTF foi obtida subtraindo-se da renda bruta todas as despesas, exceto as de mão de obra, a qual passou a ser remunerada pelo resíduo (Sá et al., 2008). A RMOF representa o valor máximo da diária que a exploração pode pagar pelo trabalho familiar.

\section{RESULTADOS E DISCUSSÃO}

\subsection{Distribuição da mão de obra dos extrativistas}

Dentre os 40 extrativistas entrevistados, a maior parte $(57,5 \%)$ informou que também trabalha na agricultura familiar, não se ocupando exclusivamente com a atividade durante todo ano; podem, dessa forma, ser classificados como produtores pluriativos, pois diversificam as atividades de geração de renda, para garantir a sua reprodução social (Schneider, 2003). Para 35\%, a principal fonte de renda é a extração da castanha, sendo esta complementada com a comercialização de farinha de mandioca produzida na entressafra. Para os $22,5 \%$ restantes, a principal fonte não é a atividade agroextrativista; estes trabalham como empregada doméstica, guarda municipal ou são aposentados.

\subsection{Coleta, transporte e comercialização da castanha-do-pará}

A mão de obra utilizada na coleta é basicamente familiar. Porém, existe diferença na organização dessa mão de obra nos três municípios. Em Oriximiná, a mão de obra mais utilizada é a de membros da família (membros de uma mesma família); em Óbidos, a maioria dos coletores trabalha sozinha e o restante, com a família; em Almeirim, foi identificado que alguns trabalhadores fazem a coleta em mutirão com pessoas de diferentes famílias (Tabela 2). Quando 
Tabela 2. Organização da mão de obra, durante a coleta da castanha-do-pará, nos municípios de Almeirim, Óbidos e Oriximiná - Mesorregião Baixo Amazonas, Estado do Pará.

Table 2. Organization of labor, during the collection of Brazil nuts in the municipalities of Almeirim, Óbidos and Oriximiná - Mesoregion Lower Amazon Pará State.

\begin{tabular}{ccccc} 
Município & \multicolumn{4}{c|}{ Mão de obra (\%) } \\
\cline { 2 - 5 } & Meeiros & Familiar & Mutirão & Trabalha Sozinho \\
\hline Oriximiná & 10 & 52 & - & 38 \\
Óbidos & - & 44 & - & 56 \\
Almeirim & 27 & 46 & 9 & 18 \\
\hline
\end{tabular}

a coleta é realizada em grupo, são amontoados os ouriços e a divisão ocorre na hora da quebra. $\mathrm{Na}$ região de rios do município de Oriximiná, a coleta é feita predominantemente por comunidades de remanescentes quilombolas, que realizam o trabalho, principalmente, com mão de obra familiar.

Nos três municípios, a distância dos castanhais varia entre 1,5 e $13 \mathrm{~km}$. Em Almeirim, as áreas mais próximas foram demarcadas pelo Instituto de Terras do Pará (ITERPA) em lotes de 10 ha para cada família. Nas áreas não definidas pelo governo, os próprios castanheiros fizeram a divisão espacial dos castanhais entre as famílias. Em Óbidos, o extrativismo é feito predominantemente por comunidades oriundas de assentamentos do Instituto Nacional de Colonização e Reforma Agrária (INCRA) e por comunidades tradicionais. No município de Oriximiná, o extrativismo é realizado, em maior parte, por comunidades quilombolas. Segundo Scoles \& Gribel (2011), o município de Oriximiná abriga importantes áreas de castanhais, que são frequentadas desde tempos pretéritos por comunidades tradicionais, ribeirinhos, indígenas e quilombolas, com a finalidade de coletar a castanha. Oliveira (2012), estudando comunidades extrativistas, identificou que, para chegar até os castanhais, pode-se levar até três dias pelos rios. A distância dos castanhais é um item de custo que os extrativistas não conseguem transferir para o preço de venda do produto.

Todo o processo dentro da floresta é realizado de forma manual, da mesma forma que Tonini \& Borges (2010) encontraram em comunidades de Rondônia. Os utensílios utilizados para fazer a coleta são: terçado, cambito ou mão-de-onça (pegador de ouriço feito a partir de pedaço de pau, utilizado para retirar os ouriços do chão e colocá-los no paneiro) e o paneiro, que é um cesto de cipó trançado, que serve para armazenar e carregar diversos produtos (Cruz, 2010). Após amontoados, independentemente do local, a maioria dos extrativistas quebra os ouriços com terçado, foice ou machado, logo após a coleta; somente uma minoria quebra os ouriços dias depois da coleta.

O transporte das amêndoas pode ser dividido em duas etapas. A primeira compreende o transporte do interior da floresta, de onde foram quebrados os ouriços, até a primeira via de melhor acessibilidade, terrestre ou fluvial. Neste percurso, a grande maioria dos extrativistas carrega as amêndoas de forma manual, ou seja, nas costas; uma menor parte utiliza animal de carga.

O transporte até a residência é realizado principalmente de canoa com motor de rabeta, com exceção do município de Óbidos, que possui os castanhais mais próximos, favorecendo o transporte manual, em animais ou em carroças com tração animal. Apenas Oriximiná tem o transporte em caminhão, que foi viabilizado pela cooperativa dos remanescentes quilombolas do município.

$\mathrm{O}$ armazenamento das amêndoas nos municípios de Óbidos e Almeirim é feito na própria residência. Em Oriximiná, além da casa, as amêndoas são armazenadas nos entrepostos. Em Óbidos, em razão de as áreas estarem mais próximas, praticamente toda a coleta é tirada da floresta após a quebra. Entretanto, em Oriximiná e em Almeirim, parte das castanhas é armazenada na floresta por um tempo de até cinco meses, período da safra. $\mathrm{O}$ armazenamento fora da floresta geralmente é feito em paióis ou depósito, com acondicionamento em sacas ou a granel.

Em Oriximiná, uma cooperativa, fundada por comunidades remanescentes de quilombolas, compra mais de um terço das castanhas. Por realizar o pagamento na hora da compra, o atravessador 
vai até a comunidade e consegue comprar parte da produção, a preço menor do que o de mercado, tornando-se um ator importante no processo de comercialização.

Os atravessadores são pessoas da própria comunidade, normalmente comerciantes, ou compradores de outros locais, que vão até a comunidade apenas para comprar a produção. Estes revendem para outros atravessadores ou para a indústria. Nos municípios de Óbidos e Almeirim, quase a totalidade da produção é comercializada com os atravessadores, em dinheiro ou em troca por outros produtos. Entretanto, uma pequena parte dos extrativistas negocia direto com a indústria. De acordo com Silva et al. (2010), o papel dos atravessadores no extrativismo vem sendo historicamente questionado. Entretanto, em algumas comunidades, a presença deles é importante, pois os extrativistas têm dificuldade para transportar a sua produção até a cidade.

\subsection{Dificuldades e potencialidades da extração da castanha-do-pará}

A principal limitação apresentada pelos extrativistas foi a falta de financiamento pelos bancos para a atividade de extrativismo de castanha. Em função disto, alguns coletores, menos capitalizados, vendem parte do produto antes da coleta e comprometem sua produção com preços abaixo do mercado, para poder custear a atividade. A ausência de apoio governamental, em decorrência da inexistência de políticas públicas para o setor, foi sinalizada como alta dificuldade nos três municípios. O preço também foi destacado, pois grande parte da produção é comercializada no período da safra, período em que o preço está mais baixo.

Em relação às facilidades no processo de coleta, verificou-se que, em Óbidos e Almeirim, os castanhais estão próximos das comunidades, apesar de suas áreas já terem diminuído por causa do desmatamento para expansão agropecuária. Em Oriximiná, os castanhais mais produtivos estão mais distantes, o que dificulta o acesso.

Nos três municípios, o transporte da produção é facilitado por atravessadores que se deslocam até as comunidades para comprar a castanha, o que, de certa forma, influencia no baixo preço do produto comercializado. Somado a isso, em Oriximiná, há o apoio da cooperativa dos extrativistas para o transporte. A venda da produção é facilitada, principalmente, pela existência de usinas de processamento no município e pela alta demanda do produto. De acordo com os coletores, não há dificuldade para obter castanhas de qualidade, especialmente em Oriximiná, onde houve um treinamento de boas práticas da coleta e do tratamento, promovido pela cooperativa dos remanescentes quilombolas. A insalubridade da atividade, embora presente em todos os municípios, não se destacou em nenhum nível de classificação.

\subsection{Análise econômica da atividade de extração da castanha-do-pará}

As atividades realizadas no interior da floresta são as que mais resultam em despesas, alcançando até $85,64 \%$ do custo total. A principal delas é a mão de obra para a coleta, que pode chegar a $68,13 \%$. Em seguida, vem o transporte até o local de armazenamento ou de comercialização, que pode ser a indústria beneficiadora, a cooperativa ou o atravessador, com o máximo de $12,86 \%$ da despesa. A quebra manual dos ouriços corresponde a $8,82 \%$ do valor investido para a extração. A infraestrutura para a coleta é básica, sem grandes investimentos e, em média, variou entre $14,36 \%$ e $22,70 \%$ em relação ao custo total (Tabela 3). Bayma et al. (2009), analisando o custo do extrativismo da castanha no Acre, encontraram valores similares, sendo $84,08 \%$ oriundos de despesas com serviços e 15,92\% de materiais.

O custo da atividade variou de acordo com a quantidade de produto extraído. Almeirim foi o município que apresentou maior custo médio/ extrativista, com $\mathrm{R} \$ 3.324,29$. Óbidos e Oriximiná tiveram um custo de $\mathrm{R} \$ 1.494,80$ e $\mathrm{R} \$ 1.229,80$, respectivamente. Embora Almeirim tenha, entre os três municípios, a menor produção comercializada de castanha ao longo da história (IBGE, 2010), apresentou a maior produtividade por extrativista em 2012, com 5.701,43 kg, o que fez aumentar também os custos. Possivelmente, o extrativismo comercial é pouco praticado nas florestas do município, o que leva a uma produção per capita maior do que os outros municípios. 
Tabela 3. Estimativa do custo por atividade/serviço/material e de sua contribuição em percentagem na atividade extrativista de castanha-do-pará nos municípios de Oriximiná, Óbidos e Almeirim, safra 2011/2012, Mesorregião Baixo Amazonas, Estado do Pará.

Table 3. Estimation of cost per activity / service / material and his contribution in percentage in the extractive activity of Brazil nut in the municipalities of Oriximiná, Óbidos and Almeirim, 2011/2012 harvest, Mesoregion Lower Amazon, Pará State.

\begin{tabular}{|c|c|c|c|c|c|c|}
\hline \multirow{2}{*}{ Discriminação } & \multicolumn{2}{|c|}{ Oriximiná } & \multicolumn{2}{|c|}{ Óbidos } & \multicolumn{2}{|c|}{ Almeirim } \\
\hline & Custo (R\$) & Custo (\%) & Custo (R\$) & Custo (\%) & Custo (R\$) & Custo (\%) \\
\hline 1 Serviços & 950,8 & 77,31 & $1.223,80$ & 81,87 & $2.846,90$ & 85,64 \\
\hline Limpeza das picadas & 0,89 & 0,07 & 3,4 & 0,23 & 0,00 & 0,00 \\
\hline Coleta de frutos & 830,14 & 67,50 & 848,3 & 56,75 & $2.264,89$ & 68,13 \\
\hline Quebra dos frutos & 0 & 0,00 & 131,9 & 8,82 & 154,67 & 4,65 \\
\hline Construção do paiol & 0 & 0,00 & 0 & 0,00 & 0 & 0,00 \\
\hline Transporte da castanha da floresta & 119,77 & 9,74 & 240,2 & 16,07 & 427,34 & 12,86 \\
\hline 2 Materiais & 279 & 22,69 & 271,00 & 18,13 & 477,39 & 14,36 \\
\hline Facão & 29,06 & 2,36 & 21,3 & 1,42 & 43,73 & 1,32 \\
\hline Lima & 11,74 & 0,95 & 15,8 & 1,06 & 19,82 & 0,60 \\
\hline Pegador de castanha do chão & 7,36 & 0,60 & 5 & 0,33 & 4,72 & 0,14 \\
\hline Paneiro para coleta de castanha & 26,25 & 2,13 & 20,4 & 1,36 & 40,6 & 1,22 \\
\hline Bota de borracha & 30,31 & 2,46 & 29,8 & 1,99 & 66,19 & 1,99 \\
\hline Calça de tecido grosso & 37,24 & 3,03 & 33,9 & 2,27 & 51,78 & 1,56 \\
\hline Camisa & 18,21 & 1,48 & 12,1 & 0,81 & 13,16 & 0,40 \\
\hline Cartucho para espingarda & 18,3 & 1,49 & 3,1 & 0,21 & 11,37 & 0,34 \\
\hline Foice & 1,5 & 0,12 & 6,9 & 0,46 & 8,93 & 0,27 \\
\hline Machado & 7,96 & 0,65 & 6,8 & 0,45 & 12,83 & 0,39 \\
\hline Balde para medição de castanha & 4,53 & 0,37 & 4,5 & 0,30 & 6,19 & 0,19 \\
\hline Sacos de aniagem & 42,03 & 3,42 & 44,8 & 3,00 & 117,98 & 3,55 \\
\hline Barbante & 1,12 & 0,09 & 8,4 & 0,56 & 8,89 & 0,27 \\
\hline Corda para amarrio de sacos & 3,39 & 0,28 & 18,2 & 1,22 & 31,2 & 0,94 \\
\hline Espingarda para segurança & 40 & 3,25 & 40 & 2,68 & 40 & 1,20 \\
\hline Custo Total & $1.229,80$ & 100,00 & $1.494,80$ & 100,00 & $3.324,29$ & 100,00 \\
\hline 3. Análise econômica & Unidade & Oriximiná & \multicolumn{2}{|c|}{ Óbidos } & \multicolumn{2}{|c|}{ Almeirim } \\
\hline Produção da coleta & $\mathrm{kg}$ & $1.753,70$ & \multicolumn{2}{|c|}{$1.932,37$} & \multicolumn{2}{|c|}{$5.201,43$} \\
\hline Preço do quilo de amêndoa & $\mathrm{R} \$$ & 0,83 & \multicolumn{2}{|c|}{0,86} & \multicolumn{2}{|c|}{0,71} \\
\hline Receita Bruta & $\mathrm{R} \$$ & $1.455,57$ & \multicolumn{2}{|c|}{$1.661,84$} & \multicolumn{2}{|c|}{$3.693,02$} \\
\hline Receita Líquida & $\mathrm{R} \$$ & 225,77 & \multicolumn{2}{|c|}{167,04} & \multicolumn{2}{|c|}{368,72} \\
\hline RMOF & $\mathrm{R} \$$ & 26,47 & \multicolumn{2}{|c|}{23,98} & \multicolumn{2}{|c|}{24,69} \\
\hline RTF & $\mathrm{R} \$$ & 831,03 & \multicolumn{2}{|c|}{983,22} & \multicolumn{2}{|c|}{$2.419,56$} \\
\hline
\end{tabular}

Quanto aos indicadores de viabilidade, a receita líquida em cada município foi $11,9 \%, 11,17 \%$ e $18,36 \%$, em relação ao custo total da atividade. A remuneração da mão de obra familiar (RMOF) foi praticamente igual ao custo de oportunidade da região de estudo. Apenas em Óbidos, a RMOF foi superior ao custo. O valor médio do custo de oportunidade informado pelos entrevistados de Almeirim, Óbidos e Oriximiná foi de R\$23,11, R\$ 19,73 e R\$ 26,4, respectivamente. Esse indicador representa o valor máximo da diária que a exploração pode pagar pelo trabalho familiar, depois de cobrir os custos dos bens e serviços (Maciel et al., 2010).

Considerando-se as opções, a composição da renda familiar dos coletores mostra que o extrativismo da castanha não é mais uma importante fonte de renda (Tabela 4).

Em relação à RTF da atividade, esta contribui com $15,0 \%$ a $17,9 \%$ para a renda mensal da família. Outras atividades são realizadas durante o ano para completar a renda. A agricultura ainda é uma atividade que garante aproximadamente um 
Tabela 4. Composição da Renda Familiar Mensal (RFM) dos coletores e atravessadores de castanha-do-pará nos municípios de Oriximiná, Óbidos e Almeirim, Mesorregião Baixo Amazonas, Estado do Pará.

Table 4. Composition of Family Income (FI) of the collectors and intermediaries of Brazil nuts in the municipality of, Oriximiná, Óbidos and Almeirim, Mesoregion Lower Amazon, Pará State.

\begin{tabular}{|c|c|c|c|c|c|c|c|}
\hline \multirow[b]{2}{*}{ Município } & \multirow[b]{2}{*}{ Perfil } & \multicolumn{5}{|c|}{ Composição da renda familiar (\%) } & \multirow{2}{*}{$\begin{array}{l}\text { RFM } \\
\text { (R\$) }\end{array}$} \\
\hline & & Castanha $^{1}$ & $\begin{array}{c}\text { Bolsa } \\
\text { governamental }\end{array}$ & Comércio & Agricultura & Outros $^{2}$ & \\
\hline \multirow{2}{*}{ Almeirim } & Atravessador & 16,1 & 0,0 & 67,3 & 1,5 & 15,1 & $6.414,17$ \\
\hline & Coletor & 17,9 & 12,03 & 0,0 & 20,0 & 50,1 & $1.128,50$ \\
\hline \multirow{2}{*}{ Óbidos } & Atravessador & 68,0 & 0,0 & 16,4 & 15,6 & 0,0 & 952,92 \\
\hline & Coletor & 18,2 & 14,5 & 0,0 & 27,4 & 49,9 & 450,13 \\
\hline \multirow{2}{*}{ Oriximiná } & Atravessador & 78,0 & 0,0 & 22,0 & 0,0 & 0,0 & $1.214,44$ \\
\hline & Coletor & 15,0 & 11,4 & 0,0 & 17,3 & 56,8 & 462,13 \\
\hline
\end{tabular}

${ }^{1}$ Foi considerado o valor da RTF; ${ }^{2}$ Salário, pensão, artesanato e pesca.

quinto da renda familiar e é capaz de fornecer, se não toda, pelo menos boa parte da alimentação, caracterizando os coletores, segundo Rego (2010), como agroextrativista ou neoextrativista.

Tonini \& Borges (2010), avaliando a extração de castanha no Estado de Rondônia, também diagnosticaram que a coleta de castanha é mais uma dentre as diversas atividades de fonte de renda das famílias rurais. As atividades de pesca e artesanato, além de salário e pensão, colaboram com mais de $50 \%$ na composição dessa renda.

No outro elo da cadeia, estão os atravessadores, que se caracterizam por possuir comércio na cidade ou nas comunidades. Sua renda é constituída, principalmente, pela comercialização da castanha, com exceção de Almeirim, que tem a principal fonte de renda oriunda de estabelecimentos comerciais, seguidos da venda da castanha. Em Óbidos, alguns praticam a agricultura e, em Almeirim, outros completam a renda com salário, pensão, artesanato ou pesca.

Nos três municípios, a maioria das amêndoas foi vendida logo após a retirada da floresta, no período de safra, que é quando os preços estão mais baixos. O preço médio variou de $R \$ 0,71 / \mathrm{kg}$ a $R \$ 0,86 / \mathrm{kg}$. O Instituto Brasileiro de Geografia e Estatística (IBGE, 2010) mostra que, no período de 1997 a 2010, o preço da castanha aumentou, porém, não de forma constante. Em 1999, conforme informações fornecidas pelos extrativistas, o preço diminuiu cerca de $38 \%$, voltando a aumentar no ano seguinte. O preço da tonelada em 2010 alcançou R\$ 1.400,00, muito acima do que foi encontrado para o ano de 2012.

Para esta diferença, admitem-se duas explicações: a primeira, o preço da castanha voltou a diminuir em relação a 2010, por uma questão de ajuste de mercado e de produção, pois naquele ano a produção foi maior do que no ano anterior, aumentando a oferta do produto, o que fez o preço diminuir naquele ano; a segunda explicação seria que a diferença pode estar na diferença de escala de obtenção dos dados de campo, uma vez que o IBGE utiliza uma escala maior de amostragem, passível de superestimar os preços de alguns locais pontuais.

\section{CONCLUSÕES}

O sistema que envolve a extração, o transporte e o armazenamento da castanha é bastante rudimentar nos três municípios estudados, com coleta e transporte manual, resultando em baixa eficiência da atividade; esta é compensada pelo uso da mão de obra familiar, que, além de diminuir os custos de produção, contribui para a reprodução social das famílias envolvidas.

Em Oriximiná, a existência da cooperativa de remanescentes de quilombolas cria algumas facilidades para a comercialização e o transporte, através da garantia de venda de um terço da produção, mas o papel desempenhado pelo atravessador resulta em maior controle sobre os elementos decisivos nesta relação de mercado. Os atravessadores controlam a 
maior parte do resultado da produção extrativa; logo, controlam o preço final do produto.

Apesar desta situação, pode-se depreender, desta pesquisa, que o extrativismo da castanha-dopará, nos três municípios estudados, apresentou viabilidade econômica para os extrativistas. No entanto, se for incluído o valor da área dos castanhais nos custos, possivelmente, pela pequena receita líquida apresentada, a atividade não teria viabilidade econômica, embora a receita líquida tenha se mostrado positiva e a remuneração da mão de obra familiar tenha se tornado a principal fonte de renda oriunda do extrativismo, para os castanheiros.

\section{AGRADECIMENTOS}

Ao professor Dr. Ricardo Scoles, pelas valiosas sugestões no decorrer do trabalho.

\section{STATUS DA SUBMISSÃO}

Recebido: 16/03/2013

Aceito: 07/10/2013

Publicado: 31/12/2013

\section{AUTOR(ES) PARA CORRESPONDÊNCIA}

\section{Adriano Araújo Silva}

Departamento de Recursos Naturais, Instituto Federal de Educação, Ciência e Tecnologia do Pará (Diretoria de Ensino) - IFPA, CEP 68020820, Santarém, PR, Brasil e-mail: adriano.silva@ifpa.edu.br

\section{REFERÊNCIAS}

Albuquerque UP, Lucena RFP, Lins Neto EMF. Seleção dos participantes da pesquisa. In: Albuquerque UP, Lucena RFP, Cunha LVFC, editores. Métodos e técnicas na pesquisa etnobiológica e etnoecológica. Recife: NUPEEA; 2010. p. 21-38.

Bayma MMAO, Santos JC, Piketty MG. Análise comparativa entre os sistemas de produção extrativista tradicional e tecnificado de castanha do Brasil ocorrente na região do alto ACRE - AC. In: Anais do $47^{\circ}$ Congresso da Sociedade Brasileira de Economia, Administração e Sociologia Rural; 2009; Porto Alegre. Rio Grande do Sul: Sociedade Brasileira de Economia, Administração e Sociologia Rural; 2009. p. 8.
Cavalcante FCS. A polícia ambiental na Amazônia: um estudo sobre as reservas extrativistas. [tese]. Campinas: Instituto de Economia, Universidade Estadual de Campinas; 2002.

Cruz TA. Mulheres da floresta do vale do Guaporé e suas interações com o meio ambiente. Revista Estudos Feministas 2010; 16(3): 913-925. http://dx.doi. org/10.1590/S0104-026X2010000300016

Fiedler NC, Soares TS, Silva GF. Produtos florestais não madeireiros: importância e manejo sustentável da floresta. Revista Ciências Exatas e Naturais 2008; 10(2): 16.

Homma AKO. Extrativismo vegetal ou plantio: qual a opção para a Amazônia? Estudos avançados 2012; 26(74): 167-186. http://dx.doi.org/10.1590/S010340142012000100012

Instituto Brasileiro de Geografia e Estatística - IBGE. Produção da extração vegetal e da silvicultura. Rio de Janeiro; 2010. v. 25, p. 11-19.

Lopes MA, Santos G, Resende MC, Carvalho FM, Cardoso MG. Estudo da rentabilidade de sistemas de produção de leite no município de Nazareno, MG. Ciência Animal Brasileira 2011; 12(1): 58-69. http:// dx.doi.org/10.5216/cab.v12i1.7725

Lorenzi H. Árvores brasileiras: manual de identificação e cultivo de plantas arbóreas nativas do Brasil. 4 ed. São Paulo: Instituto Plantarum; 2000. 384 p.

Maciel RCG, Reydon BP, Costa JA, Sales GOO. Pagando pelos serviços ambientais: uma proposta para a Reserva Extrativista Chico Mendes. Revista Acta Amazônica [online] 2010; 40(3): 489-498. http://dx.doi. org/10.1590/S0044-59672010000300007

Mori SA, Prance GT. Taxonomy, ecology, and economy botany of Brazil nut (Bertholletia excelsa Humb. e Bonpl.: Lecythidaceae). Advances in Economic Botany 1990; 8: 130-150.

Nascimento JDB Jr, Carvalho RA, Hunn S, Nazaré RFR. Castanha do Brasil como fonte de renda das áreas Quilombolas de Oriximiná, PA. Belém: Embrapa Amazônia Oriental; 2000. p. 14. (Documentos 50).

Oliveira MLR. Reflexões sobre o uso do espaço em comunidades amazônicas: uma análise da comunidade extrativista do iratapuru. Revista Brasileira de Economia Doméstica 2012; 23(1): 121-146.

Pará. Secretaria de Estado de Planejamento, Orçamento e Finanças - SEPOF. Estatística Municipal: Almeirim. Belém; 2012a. p. 7-8.

Pará. Secretaria de Estado de Planejamento, Orçamento e Finanças - SEPOF. Estatística Municipal: Óbidos. Belém; 2012b. p. 7-8.

Pará. Secretaria de Estado de Planejamento, Orçamento e Finanças - SEPOF. Estatística Municipal: Oriximiná. Belém; 2012c. p. 7-8. 
Procópio A. Subdesenvolvimento sustentável. Curitiba: Juruá; 2007. 335 p.

Rego JF. Amazônia: do extrativismo ao neoextrativismo [online]. 2010. 8 p. [cited 2012 nov. 06]. Available from: http://eduardoeginacarli.blogspot.com.br/2010/07/ amazonia-do-extrativismo-ao.html.

Sá CP, Bayma MMA, Wadt LHO. Coeficientes técnicos, custo e rentabilidade para a coleta de castanha-do-brasil no Estado do Acre: sistema de produção melhorado. Rio Branco: Embrapa Acre; 2008. 4 p. (Comunicado Técnico 168).

Salomão RP. Densidade, estrutura e distribuição espacial de castanheira-do-brasil (Bertholletia excelsa H. \& B.) em dois platôs de floresta ombrófila densa na Amazônia setentrional brasileira. Boletim do Museu Paraense Emílio Goeldi. Ciências Naturais 2009; 4(1): 11-25.

Schneider S. A pluriatividade na agricultura familiar. Porto Alegre: Ed. UFRGS; 2003. 253 p.

Scoles R, Gribel R, Klein GN. Crescimento e sobrevivência de castanheira (Bertholletia excelsa Bonpl.) em diferentes condições ambientais na região do rio Trombetas, Oriximiná, Pará. Boletim do Museu Paraense Emílio Goeldi. Ciências Naturais 2008; 6(3): 273-293.

Scoles R, Gribel R. Population structure of brazil nut (Bertholletia excelsa, Lecythidaceae) stands in two areas with different occupation histories in the Brazilian Amazon. Human Ecology 2011; 39: 455-464. http:// dx.doi.org/10.1007/s10745-011-9412-0

Shackleton CM, Shackleton SE, Buiten E, Bird N. The importance of dry woodlands and forests in rurl livelihoods and poverty alleviation in South Africa. Forest Policy and Economics 2007; 9(5): 558-577. http:// dx.doi.org/10.1016/j.forpol.2006.03.004

Silva TM, Jardim FCS, Silva MS, Shanley P. O mercado de amêndoas de dipteryx odorada (cumaru) no estado do Pará. Floresta 2010; 40(3): 603-614.

Tonini H, Borges RA. O extrativismo da castanha-dobrasil na região do Baixo Rio Branco (RR). Boa Vista: Embrapa Roraima; 2010. 20 p. (Documentos, n. 39).

World Health Organization - WHO. Division of Mental Health. Qualitative research for health programmes. Geneva: World Health Organization; 1994. 